\title{
Perfil lipídico e maciez da carne de coxa e sobrecoxa de frangos de corte alimentados com rações contendo diferentes fontes lipídicas
}

\author{
Alexandra Potença ${ }^{1}$, Alice Eiko Murakami ${ }^{2}$, Makoto Matsushita ${ }^{3}$, Jesui Vergílio Visentainer ${ }^{3}$, \\ Elias Nunes Martins ${ }^{2}$, Antonio Claudio Furlan²
}

1 Pós-Graduação em Zootecnia da Universidade Estadual de Maringá/UEM, Maringá, PR.
2 Departamento de Zootecnia da Universidade Estadual de Maringá/UEM, Maringá, PR.
${ }^{3}$ Departamento de Química da Universidade Estadual de Maringá/UEM, Maringá, PR.

RESUMO - Foram conduzidos dois experimentos com o objetivo de avaliar a qualidade e o perfil de ácidos graxos da carne de coxa e sobrecoxa em frangos de corte, no período de 1 a 42 dias de idade. No experimento 1, foi adotado delineamento experimental inteiramente casualizado, com quatro dietas, oito repetições e 49 aves por unidade experimental. Na fase inicial, as aves receberam rações formuladas com óleo de soja; óleo de algodão; óleo de vísceras ou sebo bovino e, na fase de crescimento, cada uma dessas dietas foi desmembrada em duas, de modo que um grupo de aves continuou a receber a mesma fonte de óleo utilizada na fase anterior, enquanto o outro grupo passou a receber óleo de soja na dieta. Nessa fase, foi utilizado um delineamento inteiramente casualizado, com sete dietas, cada uma com quatro repetições. Houve influência das dietas no perfil de ácidos graxos da coxa. No experimento 2, durante a fase inicial (1 a 21 dias), as aves receberam a mesma ração, contendo 3\% de óleo de soja e, na fase de crescimento (22 a 42 dias), em um delineamento inteiramente casualizado, com cinco dietas, cada uma com uma com uma fonte lipídica (óleo de soja, óleo de canola, óleo de girassol, óleo de vísceras ou sebo bovino) seis repetições e 30 aves/unidade experimental, fontes lipídicas. Não foi verificado efeito das dietas sobre o pH e a força de cisalhamento. As dietas influenciaram, no entanto, o perfil de ácidos graxos da coxa, pois, de acordo com os resultados, o enriquecimento das rações com fontes de óleo promoveu modificações na composição lipídica na carne da coxa dos frangos, de modo que o melhor perfil de ácidos graxos foi observado na carne dos animais alimentados com a ração contendo óleo de soja.

Palavras-chave: ácidos graxos, perfil lipídico, qualidade da carne de frangos de corte

\section{Lipidic profile and tenderness of thigh and drumstick meat of broilers fed diets supplemented with different lipid sources}

\begin{abstract}
Two experiments were carried out to evaluate the quality and profile of fatty acids in the thigh and drumstick of broiler chickens, from one to 42 days of age. In the experiment 1 , a complete randomized design, with four diets, eight replicates and 49 birds per experimental unit was used. In the starter phase, birds received diets formulated with soybean oil, cottonseed oil, poultry offal oil, or beef tallow, and during the growing phase, each one of these diets was dismembered in two diets, so one group of birds kept receiving the same oil source used in the previous phase while the other group started to receive soybean oil in the diet. In this phase, it was used a complete random design with seven diets, each one with four replicates. There was an effect of the diets on the profile of the fatty acids in the thigh. In the experiment 2, during the starter phase (from 1 to 21 days of age), the birds received the same diets with 3\% of soybean oil, and in the growing phase (from 22 to 42 days of age), they received five diets each one with a lipidic source (soybean, canola oil, sunflower oil, poultry offal oil and beef tallow) evaluated in a complete random design with six replicates and 30 birds per experimental unity. It was not observed effect of the diets on $\mathrm{pH}$ and shear force. However, diets influence the profile of fatty acids in the thigh because accordingly to the results, the increment of the rations with oil sources promote changes on lipid composition of the broiler thigh meat, so the best profile of fatty acids is observed in the meat of animals fed ration containing soybean oil.
\end{abstract}

Key Words: fatty acids, lipid profile, meat quality of broilers

\section{Introdução}

As recentes descobertas na área da saúde têm mudado os conceitos e os hábitos relacionados à alimentação humana. Essas mudanças referem-se, principalmente, a ingestão da gordura presente na carne. Os aspectos negativos da utilização da carne estão associados à concentração de ácidos graxos saturados (Laborde et al., 2001). Embora seja necessário à saúde humana (French et al., 2000), o consumo de AGS está relacionado com altas 
concentrações de LDL-colesterol sérico (lipoproteína de baixa densidade), um fator de risco para as doenças do coração (Rique et al., 2002). A carne branca vem tendo seu consumo aumentado por estar sendo considerada de melhor qualidade (menor teor de gorduras) que as carnes vermelhas (Nascif et al., 2004).

A inclusão de óleo na dieta de animais foi primeiramente estudada com o objetivo de aumentar a densidade energética (Andreotti et al., 2004; Junqueira et al., 2005; Costa et al., 2008). Contudo, modificações nas características dietéticas, através da inclusão de lipídios, têm sido estudadas com o intuito de melhorar não apenas a qualidade nutricional das dietas, mas também o efeito que tais alterações promovem na qualidade dos produtos de origem animal (Lara et al., 2006; Crespo \& Esteve-Garcia, 2002; Pinchason et al., 1992). Em monogástricos, a composição lipídica tecidual reflete a alimentação e pode ser alterada pela manipulação da dieta (Ribeiro et al., 2008).

O enriquecimento da carne com ácidos graxos n-3 é uma oportunidade para que o setor da produção de frangos adicione o valor a seu produto (Zuidhof et al., 2009).

Quando a concentração de ácido linoleico (n-6) não está em equilíbrio com o ácido linolênico (n-3), problemas podem surgir porque estes ácidos graxos competem pelas mesmas enzimas nos processos de alongamento e dessaturação, pois são comuns em ambas as vias metabólicas, possibilitando que suas diferenças estruturais produzam eicosanoides com funções diferenciadas (Fagundes, 2002). Para adequada razão de n-6/n-3 na dieta, é necessária a introdução de alimentos enriquecidos com n-3. Alguns estudos (Lara et al., 2006; Crespo \& EsteveGarcia, 2002; Pinchason et al.,1992) têm demonstrado que é possível alterar o perfil lipídico da carne de frangos de corte por meio do tipo de lipídio adicionado à ração.

Os ácidos graxos poliinsaturados podem influenciar indiretamente na síntese de colágeno. Alguns estudos (Tarrant, 2001; Bailey, 1985) têm indicado que a integridade das ligações cruzadas de colágeno está relacionada com a textura da carne. Assim, realizou-se este trabalho com o objetivo de avaliar a utilização de fontes de lipídios nas rações sobre a deposição de gordura abdominal, perfil de ácidos graxos, $\mathrm{pH}$ e força de cisalhamento da carne de frangos de corte.

\section{Material e Métodos}

Dois experimentos foram conduzidos no setor de avicultura. No experimento 1 foram utilizados 1.568 pintos de cortes machos de 1 dia de idade (peso médio 47,54 g), da linhagem Cobb. As aves foram alojadas num galpão convencional de $30 \mathrm{~m}$ de comprimento e $8 \mathrm{~m}$ de largura, com cobertura de telha francesa e lanternim, piso concreto e paredes laterais de alvenaria com $40 \mathrm{~cm}$ de altura, sendo o restante da parede completa com tela de arame até o telhado, com cortinas móveis.

O galpão foi dividido em 30 boxes de $6,3 \mathrm{~m}^{2}$ cada com capacidade para 49 aves cada. A cama utilizada foi de palha de arroz e as aves foram vacinadas no incubatório contra a doença de marek. Após o alojamento não receberam nenhuma vacina. Foi adotado um programa de luz contínuo durante os primeiros dez dias e o restante do período experimental com 23 horas de luz/dia. Na fase inicial foram utilizados comedouros infantis e bebedouros do tipo copo de pressão até o quinto dia de idade, sendo os comedouros substituídos gradativamente pelos comedouros tubulares e bebedouros automáticos do tipo pendular.

Em cada boxe, foi utilizado um circulo de proteção e uma campânula como fonte de aquecimento para os pintinhos. Água e ração foram fornecidas ad libitum em programa de alimentação dividido em duas fases: inicial do $1^{\underline{0}}$ ao $21^{0}$ dia de idade e crescimento, do $22 \underline{0}$ ao $42 \underline{O}$ dia de idade.

As aves receberam rações formuladas com diferentes fontes de lipídios, sendo óleo de soja, óleo de algodão, óleo de vísceras e sebo bovino, na fase inicial. Na fase de crescimento, cada dieta utilizada na fase inicial foi desmembrada em duas dietas, de modo que um grupo de aves continuou a receber a mesma fonte de óleo utilizada na fase anterior e outro grupo passou a receber óleo de soja na dieta. Este desmembramento teve como objetivo avaliar se a fase em que é fornecida a fonte lipídica e se o tempo de fornecimento têm influência sobre o perfil de ácidos graxos da carne de coxa e sobrecoxa. O nível de inclusão da fonte lipídica na dieta foi de 3\% na fase de 1 a 21 e 4,5\% de 22 a 42 dias.

As rações foram formuladas de modo a atender as exigências nutricionais para as fases inicial e de crescimento, de acordo com de Rostagno et al. (2005), de forma a serem isoenergéticas e isonutritivas para os nutrientes (Tabela 1).

Para avaliação do perfil de ácidos graxos, aos 21 e 42 dias de idade, duas aves por unidade experimental foram retiradas ao acaso e sacrificadas por deslocamento cervical. As coxas e sobrecoxas foram coletadas e armazenadas a $-18^{\circ} \mathrm{C}$ até o início das análises do perfil de ácidos graxos.

No experimento 2 foram utilizados 900 pintos de corte machos de um dia de idade (peso médio 49,22 g) da linhagem Cobb. As aves foram alojadas num galpão convencional com cobertura de telha francesa, piso concreto e paredes laterais de alvenaria com $40 \mathrm{~cm}$ de altura, sendo o restante da parede completada com tela de 
arame até o telhado, com cortinas móveis. O galpão foi dividido em 30 boxes de $3,8 \mathrm{~m}^{2}$ cada, com capacidade para 30 aves cada.

$\mathrm{O}$ manejo na fase inicial deste experimento segue o descrito no experimento 1 para esta mesma fase.

Na fase de 1 a 21 dias de idade, as aves receberam a mesma ração, tendo como fonte de lipídios o óleo de soja com 3\% de inclusão na ração. $\mathrm{Na}$ fase de crescimento (22 a 42 dias de idade) foi adotado um delineamento inteiramente casualizado com cinco dietas, seis repetições com 30 aves por unidade experimental. As aves receberam rações formuladas com diferentes fontes lipídicas: óleo de soja, óleo de canola, óleo de girassol, óleo de vísceras e sebo bovino. Todas as rações na fase de crescimento foram formuladas com 4,5\% da fonte lipídica.

As rações foram formuladas para atender às exigências nutricionais para as fases inicial ( 1 a 21 dias de idade) e de crescimento (22 a 42 dias de idade), de acordo com exigências descritas por Rostagno et al. (2005), de forma a serem isoenergéticas e isonutritivas (Tabela 2).
Aos 42 dias de idade, duas aves por unidade experimental ao acaso, foram sacrificadas por deslocamento cervical. Foram coletados peito (análise de $\mathrm{pH}$ e força de cisalhamento) e coxa e sobrecoxa direitas (perfil de ácidos graxos).

As coxas e sobrecoxas direitas e sem pele foram coletadas e armazenadas a $-18^{\circ} \mathrm{C}$ até o início das análises do perfil de ácidos graxos. Para análise de força de cisalhamento, os filés do peito de duas aves por unidade experimental foram armazenados em papel alumínio e sacos plásticos e congelados a $-18^{\circ} \mathrm{C}$ até a realização das análises.

A determinação do $\mathrm{pH}$ foi realizada diretamente no filé do peito resfriado de duas aves por unidade experimental, com auxílio de um peagâmetro TECNAL ${ }^{\circledR} 4$ horas post mortem. O ponto de incisão do eletrodo foi na parte cranial ventral do filé.

As análises do perfil lipídico das rações e das carnes foram realizadas no Laboratório de Química da Universidade Estadual de Maringá. As coxas e sobrecoxas direitas foram descongeladas, descarnadas, os ossos removidos e a carne

Tabela 1 - Composição das rações fornecidas nas fases inicial e de crescimento no experimento 1

\begin{tabular}{|c|c|c|c|c|c|c|c|c|}
\hline & \multicolumn{4}{|c|}{ Fase inicial (1 a 21 dias) } & \multicolumn{4}{|c|}{ Fase de crescimento (22 a 42 dias) } \\
\hline Milho & 55,50 & 55,5 & 55,61 & 56,60 & 60,40 & 60,40 & 60,57 & 62,51 \\
\hline Farelo soja $45 \%$ & 36,73 & 36,73 & 36,71 & 36,53 & 29,60 & 29,60 & 29,57 & 29,21 \\
\hline Fosfato bicálcico & 1,84 & 1,84 & 1,84 & 1,83 & 1,61 & 1,61 & 1,61 & 1,61 \\
\hline Sal comum & 0,44 & 0,44 & 0,44 & 0,44 & 0,42 & 0,42 & 0,42 & 0,42 \\
\hline DL-metionina 99 & 0,19 & 0,19 & 0,19 & 0,19 & 0,23 & 0,23 & 0,23 & 0,22 \\
\hline L- lisina 78,8 & 0,07 & 0,07 & 0,07 & 0,08 & 0,21 & 0,21 & 0,21 & 0,22 \\
\hline Suplemento mineral/vitamínico ${ }^{1}$ & 0,15 & 0,15 & 0,15 & 0,15 & 0,00 & 0,00 & 0,00 & 0,00 \\
\hline Suplemento mineral/vitamínico ${ }^{2}$ & 0,00 & 0,00 & 0,00 & 0,00 & 0,40 & 0,40 & 0,40 & 0,40 \\
\hline Butil-hidroxi-tolueno $^{3}$ & 0,01 & 0,01 & 0,01 & 0,01 & 0,01 & 0,01 & 0,01 & 0,01 \\
\hline Energia metabolizável (kcal/kg) & 2.972 & 2.972 & 2.972 & 2.972 & 3.125 & 3.125 & 3.125 & 3.125 \\
\hline Metionina digestivel (\%) & 0,30 & 0,30 & 0,30 & 0,30 & 0,27 & 0,27 & 0,27 & 0,27 \\
\hline Metionina + cistina digestíveis (\%) & 0,88 & 0,88 & 0,88 & 0,88 & 0,75 & 0,75 & 0,75 & 0,75 \\
\hline Lisina digestivel (\%) & 1,24 & 1,24 & 1,24 & 1,24 & 1,05 & 1,05 & 1,05 & 1,05 \\
\hline Treonina digestível (\%) & 0,73 & 0,73 & 0,73 & 0,73 & 0,62 & 0,62 & 0,62 & 0,62 \\
\hline Triptofano digestível (\%) & 0,24 & 0,24 & 0,24 & 0,24 & 0,20 & 0,20 & 0,20 & 0,20 \\
\hline Cálcio (\%) & 0,91 & 0,91 & 0,91 & 0,91 & 0,80 & 0,80 & 0,80 & 0,80 \\
\hline Fósforo disponível (\%) & 0,46 & 0,46 & 0,46 & 0,46 & 0,40 & 0,40 & 0,40 & 0,40 \\
\hline Sódio (\%) & 0,22 & 0,22 & 0,22 & 0,22 & 0,20 & 0,20 & 0,20 & 0,20 \\
\hline Potássio (\%) & 0,83 & 0,83 & 0,83 & 0,83 & 0,71 & 0,71 & 0,71 & 0,71 \\
\hline Cloro (\%) & 0,31 & 0,31 & 0,31 & 0,31 & 0,31 & 0,31 & 0,31 & 0,31 \\
\hline
\end{tabular}


Tabela 2 - Composição das rações fornecidas nas fases inicial e de crescimento no experimento 2

\begin{tabular}{|c|c|c|c|c|c|c|}
\hline & \multirow{2}{*}{$\begin{array}{c}\text { Fase } \\
\text { inicial } \\
(1 \text { a } 21 \text { dias }) \\
\text { Óleo soja }\end{array}$} & \multicolumn{5}{|c|}{ Fase de crescimento (22 a 42 dias) } \\
\hline & & Óleo soja & Óleo canola & Óleo girassol & Óleo vísceras & Sebo bovino \\
\hline \multicolumn{7}{|l|}{ Composição em ingredientes } \\
\hline Milho & 55,50 & 60,40 & 60,40 & 60,40 & 60,57 & 62,51 \\
\hline Farelo soja $45 \%$ & 36,73 & 29,60 & 29,60 & 29,60 & 29,57 & 29,21 \\
\hline Óleo & 3,00 & 4,50 & 4,50 & 4,50 & 4,50 & 4,50 \\
\hline Sal comum & 0,44 & 0,42 & 0,42 & 0,42 & 0,42 & 0,42 \\
\hline DL-metionina $98 \%$ & 0,19 & 0,23 & 0,23 & 0,23 & 0,23 & 0,22 \\
\hline L- lisina 78,8 & 0,07 & 0,21 & 0,21 & 0,21 & 0,21 & 0,22 \\
\hline Suplemento mineral vitamínico ${ }^{1}$ & 0,15 & 0,00 & 0,00 & 0,00 & 0,00 & 0,00 \\
\hline Suplemento mineral vitamínico ${ }^{2}$ & 0,00 & 0,40 & 0,40 & 0,40 & 0,40 & 0,40 \\
\hline Gordura $(\%)$ & 5,60 & 7,15 & 7,15 & 7,15 & 7,13 & 7,21 \\
\hline Energia metabolizável (kcal/kg) & 2.972 & 3.125 & 3.125 & 3.125 & 3.125 & 3.125 \\
\hline Metionína digestível (\%) & 0,30 & 0,27 & 0,27 & 0,27 & 0,27 & 0,27 \\
\hline Metionina + cistina digestíveis (\%) & 0,88 & 0,75 & 0,75 & 0,75 & 0,75 & 0,75 \\
\hline Lisina digestível (\%) & 1,24 & 1,05 & 1,05 & 1,05 & 1,05 & 1,05 \\
\hline Treonina digestível (\%) & 0,73 & 0,62 & 0,62 & 0,62 & 0,62 & 0,62 \\
\hline Triptofano digestível (\%) & 0,24 & 0,20 & 0,20 & 0,20 & 0,20 & 0,20 \\
\hline Cálcio (\%) & 0,91 & 0,80 & 0,80 & 0,80 & 0,80 & 0,80 \\
\hline Fósforo disponível (\%) & 0,46 & 0,40 & 0,40 & 0,40 & 0,40 & 0,40 \\
\hline Sódio (\%) & 0,22 & 0,20 & 0,20 & 0,20 & 0,20 & 0,20 \\
\hline Potássio (\%) & 0,83 & 0,71 & 0,71 & 0,71 & 0,71 & 0,71 \\
\hline Cloro $(\%)$ & 0,31 & 0,31 & 0,31 & 0,31 & 0,31 & 0,31 \\
\hline
\end{tabular}

foi triturada para ser analisada. Para análise de perfil lipídico foi realizada a extração de lipídios totais segundo método descrito por Bligh \& Dyer (1959). Para análise do perfil de ácidos graxos da ração foi realizada a correção da umidade para $80 \%$.

A transesterificação dos triacilgliceróis das amostras foi realizada conforme o método 5509 da ISO (1978). Os ésteres de ácidos graxos das amostras foram analisados por Cromatógrafo Shimadzu 14A de Fase gasosa, equipado com detector de ionização de chama e coluna capilar de sílica fundida.

As áreas de picos foram determinadas pelo programa Clariet, e as identificações dos picos foram realizadas pela comparação dos tempos de retenção com os padrões de ésteres metílicos de ácidos graxos e os dados expressos em porcentagem do ácido graxo em relação aos lipídios totais. Como lipídios totais foram considerados os ácidos graxos saturados C14:0 (mirístico), C16:0 (palmítico), C18:0 (esteárico), os ácidos graxo monoinsaturados C16:1 (palmitoleico), C18:1 (oleico) e os ácidos graxos poliinsaturados C18:2n-6 (linoleico) e C18:3n-3 (linolênico). Sendo que os mais importantes $\omega$-3 na nutrição humana são DHA 22:6, EPA 20:5 e $\alpha$-linolênico, que serve como precursor de EPA e DHA (Gebauer et al., 2006; Burdge, 2004; Arterburn et al., 2006).

A força de cisalhamento foi realizada no Laboratório de Qualidade de Carne do Departamento de Nutrição Animal da Universidade Estadual de Maringá, Campus de Umuarama, PR.

As amostras foram descongeladas em temperatura ambiente, desembaladas, pesadas e embaladas novamente, individualmente em papel alumínio e assadas em chapa aquecedora, pré-aquecida a $170^{\circ} \mathrm{C}$, até atingir $80^{\circ} \mathrm{C}$ no centro geométrico, monitorada por termômetro (Morgan et al., 1993). Foram secas com papel absorvente e esfriadas à temperatura ambiente.

Os filés assados foram deixados à temperatura ambiente por no mínimo duas horas. Posteriormente, as amostras foram aparadas e cortadas em três retângulos $(1,5 \times 1,5 \times 3,0 \mathrm{~cm})$, para determinação da maciez. Na 
determinação da força de cisalhamento utilizou-se o aparelho mecânico Warner-Bratzler Shear Force, com capacidade de $20 \mathrm{~kg}$ e velocidade do seccionador de $20 \mathrm{~cm} / \mathrm{min}$, que mede a força de cisalhamento da amostra, em kgf (Kerth et al., 1995).

Os dados de $\mathrm{pH}$, força de cisalhamento e perfil de ácidos graxos foram submetidos às análises de variância e as diferenças entre as médias avaliadas por meio do teste Tukey a 5\% de probabilidade pelo Programa de Análises Estatísticas-SAEG(UFV, 1993).

\section{Resultados e Discussão}

Os ácidos linoleico (18:2n-6) e alfa-linolênico (18:3n-3) foram os representantes dos ácidos graxos das séries n-6 e $\mathrm{n}-3$, respectivamente, encontrados em maiores proporções nas rações experimentais (Tabela 3 ).

De acordo com os resultados encontrados nas análises, foi observada influência da fonte lipídica da dieta sobre o perfil de ácidos graxos da carne da coxa (Tabelas 4 e 5).

$\mathrm{Na}$ fase inicial, as aves que receberam óleo de soja na ração tiveram menor deposição de ácidos graxos saturados (AGS) quando comparadas às demais fontes. As aves suplementadas com sebo bovino apresentaram porcentagens superiores dos ácidos graxos saturados mirístico e esteárico. Já na carne da coxa e sobrecoxa das aves alimentadas com óleo de soja, os ácidos graxos saturados palmítico e esteárico apresentaram-se em quantidades inferiores. Estes dados estão de acordo com o apresentado por Crespo \& Esteve-Garcia, (2002) que encontraram uma quantidade maior de ácidos graxos saturados nas aves alimentadas com sebo bovino. Embora os ácidos graxos saturados e ácidos graxos monoinsaturados (AGMI) sejam necessários à saúde humana, segundo French et al. (2000), o consumo de ácidos graxos saturados está ligado às altas concentrações de LDL sérico, que é fator de risco para as doenças do coração.

A concentração dos ácidos graxos monoinsaturados (palmitoleico e oleico) foi significativamente maior nas aves suplementadas com lipídios de origem animal na ração. Estes resultados são condizentes com os encontrados por Lara et al. (2006). Observa-se que as maiores concentrações do palmitoleico foram encontradas nas coxas das aves alimentadas com óleo de vísceras e sebo bovino, já para o ácido oleico o maior teor foi identificado nas aves que receberam óleo de algodão na ração.

Quanto aos ácidos graxos poliinsaturados (linoleico e linolênico), teores superiores foram apresentados na carne da coxa das aves que consumiram rações contendo óleo de soja e óleo de algodão. Já para o ácido linolênico, a maior

Tabela 3 - Perfil de ácidos graxos das rações experimentais na fase inicial e de crescimento do experimento 1

\begin{tabular}{|c|c|c|c|c|}
\hline Perfil lipídico & Óleo soja & Óleo algodão & Óleo vísceras & Sebo bovino \\
\hline & \multicolumn{4}{|c|}{ Fase inicial (1 a 21 dias) } \\
\hline C14:0 (mirístico) & 0,07 & 0,32 & 0,31 & 1,28 \\
\hline C16:0 (palmítico) & 12,40 & 17,45 & 19,07 & 21,31 \\
\hline C16:1 (palmitoleico) & 0,14 & 0,24 & 3,103 & 0,87 \\
\hline C18:0 (esteárico) & 3,16 & 2,452 & 4,610 & 18,74 \\
\hline C18:1 (oleico) & 28,82 & 23,28 & 37,81 & 34,34 \\
\hline C18:2n-6 (linoleico) & 51,82 & 55,15 & 33,67 & 22,42 \\
\hline C18:3n-3 (linolênico) & 3,58 & 1,108 & 1,429 & 1,03 \\
\hline$\omega 6: \omega 3^{1}$ & 14,46 & 49,89 & 23,56 & 21,78 \\
\hline Ácidos graxos saturados & 15,63 & 20,22 & 23,99 & 41,33 \\
\hline Ácidos graxos monoinsaturados & 28,96 & 23,52 & 40,91 & 35,22 \\
\hline Ácidos graxos poliinsaturados & 55,41 & 56,26 & 35,10 & 23,45 \\
\hline \multirow[t]{2}{*}{ Relação poliinsaturados/saturados } & 3,54 & 2,78 & 1,46 & 0,57 \\
\hline & \multicolumn{4}{|c|}{ Fase de crescimento (22 a 42 dias) } \\
\hline C14:0 (mirístico) & 0,06 & 0,35 & 0,35 & 1,70 \\
\hline C16:0 (palmítico) & 11,65 & 18,31 & 20,37 & 21,15 \\
\hline C16:1 (palmitoleico) & 0,14 & 0,42 & 3,58 & 0,96 \\
\hline C18:0 (esteárico) & 3,27 & 2,49 & 4,89 & 21,13 \\
\hline C18:1 (oleico) & 28,31 & 22,44 & 39,17 & 35,60 \\
\hline C18:2n-6 (linoleico) & 52,73 & 55,11 & 30,42 & 18,63 \\
\hline C18:3n-3 (linolênico) & 3,84 & 0,88 & 1,22 & 0,82 \\
\hline$\omega 6: \omega 3$ & 13,71 & 62,37 & 24,93 & 22,65 \\
\hline Ácidos graxos saturados & 14,98 & 21,14 & 25,62 & 43,98 \\
\hline Ácidos graxos monoinsaturados & 28,44 & 22,86 & 42,74 & 36,56 \\
\hline Ácidos graxos poliinsaturados & 56,57 & 56,00 & 31,64 & 19,45 \\
\hline Relação poliinsaturados/saturados & 3,78 & 2,65 & 1,24 & 0,44 \\
\hline
\end{tabular}

Dados obtidos com base na percentagem de área de cada ácido graxo em relação à área total dos ácidos graxos identificados.

1 66: 13 : relação ácidos graxos ômega 6: ácidos graxos ômega 3. 
deposição foi nas aves que consumiram óleo de soja e menor nas que consumiram sebo bovino ou óleo de algodão.

Estudos clínicos realizados em humanos têm recomendado o aumento dos ácidos graxos monoinsaturados e ácidos graxos poliinsaurados na dieta, para os indivíduos em geral, e principalmente aqueles com doença crônica (Watts et al., 1996; Oliver, 1997). As maiores organizações de saúde dos Estados Unidos têm proposto a proporção de 1:2:1,5 respectivamente para ácidos graxos saturados, ácidos graxos monoinsaturados e ácidos graxos poliinsaturados, na prevenção e tratamento de dislipidemias, e hipertensão (Metz et al., 1997), porém nenhum dos resultados encontrados com os tratamentos estudados apresentou esta proporção na carne.

As aves alimentadas com óleo de algodão tiveram significativamente a pior relação de $\omega 6: \omega 3$, sendo a melhor relação encontrada nas aves suplementadas com óleo de soja. O consumo diário destes ácidos foi discutido por Simopoulos et al. (1999), que destacaram a importância de reduzir os ácidos graxos poliinsaturados n-6. Segundo os mesmos autores, ainda que os $n-3$ sejam aumentados na dieta de adultos e recém-nascidos visando a manutenção da saúde, este fato se faz necessário para reduzir os efeitos adversos do excesso do ácido araquidônico. Esse excesso pode ocorrer quando muito ácido linoleico e araquidônico estão presentes na dieta, somando com um inadequado fornecimento de n-3. Portanto, acrescentando na dieta ácidos graxos poliinsaturados n-3 e diminuindo certos óleos vegetais com alto conteúdo de linoleico, pode-se obter uma melhora na proporção $\omega 6: \omega 3$ (Harris, 1997).

Na fase inicial, a melhor fonte de lipídios estudada foi o óleo de soja, que apresentou a maior razão de ácidos graxos saturados/ácidos graxos poliinsaturados e a melhor relação de $\omega 6: \omega 3$ na carne da coxa quando comparada às outras aves alimentadas com as outras fontes estudadas.
Na fase de crescimento, houve influência da relação AGPI/AGS e $\omega 6: \omega 3$ causadas pela fonte lipídica da ração na deposição de ácidos graxos saturados, ácidos graxos monoinsaturados e ácidos graxos poliinsaturados (Tabela 5).

As aves que receberam rações em que a fonte de lipídios na fase de crescimento foi diferente da fonte utilizada no período inicial tiveram seu perfil de ácidos graxos da carne iguais ou próximos do perfil da fonte recebida na segunda fase. Entretanto, nas aves alimentadas com óleo de vísceras, o ácido oleico apresentou valores iguais aos dois óleos. O mesmo fato foi observado para o óleo de algodão, que para a maioria dos ácidos (palmitoleico, esteárico, oleico linoleico, ácidos graxos monoinsaturados e ácidos graxos poliinsaturados) tiveram valores iguais à primeira e à segunda fonte. Isto indica que a fase de crescimento tem maior influência sobre a deposição de ácidos graxos na carne, provavelmente devido à maior taxa de deposição de gordura neste período quando comparada à fase inicial.

A maior concentração de ácidos graxos saturados (C14:0, C16:0, C18:0) na fase final de produção foi apresentada pelas aves alimentadas por período integral com óleo de vísceras, sebo bovino e óleo de algodão, seguidas pelas que receberam óleo de soja no período de crescimento e menor naquelas que consumiram óleo de soja na fase inicial e de crescimento.

O teor de AGMI foi superior na carne da coxa das aves alimentadas com rações contendo lipídios de origem animal na fase inicial e de crescimento, no entanto diminuiu nas aves alimentadas por estas fontes na fase inicial e óleo de soja na fase de crescimento.

A maior relação de AGPI/AGS foi apresentada nas aves que receberam óleo de soja e óleo de algodão na dieta por período integral. As aves que consumiram sebo bovino e óleo de vísceras na fase inicial e de crescimento tiveram a

Tabela 4 - Perfil de ácidos graxos da carne da coxa e sobrecoxa de frangos na fase de 1 a 21 dias (experimento 1)

\begin{tabular}{|c|c|c|c|c|c|c|}
\hline Perfil lipídico & Óleo de soja & Óleo de algodão & Óleo de vísceras & Sebo bovino & CV (\%) & $\mathrm{F}$ \\
\hline C14:0 (mirístico) & $0,36 \pm 0,02 b$ & $0,48 \pm 0,02 b$ & $0,61 \pm 0,12 b$ & $0,98 \pm 0,04 a$ & 22,25 & $16,00 * *$ \\
\hline C16:0 (palmítico) & $21,94 \pm 0,50 b$ & $24,42 \pm 0,44 a$ & $24,88 \pm 0,17 a$ & $24,23 \pm 0,04 a$ & 2,89 & $14,58 * *$ \\
\hline C16:1 (palmitoleico) & $4,25 \pm 0,23 b$ & $3,65 \pm 0,28 b$ & $5,56 \pm 0,35 a$ & $5,53 \pm 0,30 \mathrm{a}$ & 12,32 & $10,56 * *$ \\
\hline C18:0 (esteárico) & $5,54 \pm 0,20 c$ & $6,58 \pm 0,23 b$ & $6,52 \pm 0,37 b c$ & $7,80 \pm 0,13 a$ & 7,31 & $14,75 * *$ \\
\hline C18:1 (oleico) & $36,68 \pm 0,67 c$ & $33,63 \pm 0,33 d$ & $41,25 \pm 0,67 b$ & $45,21 \pm 0,54 a$ & 2,91 & $79,46 * *$ \\
\hline C18:2n-6 (linoleico) & $29,39 \pm 0,45 a$ & $30,51 \pm 0,49 a$ & $20,35 \pm 0,51 b$ & $15,53 \pm 0,29 c$ & 3,69 & $267,03 * *$ \\
\hline C18:3n-3 (linolênico) & $1,84 \pm 0,046 a$ & $0,73 \pm 0,01 \mathrm{bc}$ & $0,82 \pm 0,01 b$ & $0,70 \pm 0,01 c$ & 4,90 & $476,65 * *$ \\
\hline$\omega 6: \omega 3^{1}$ & $15,98 \pm 0,24 d$ & $42,09 \pm 0,55 a$ & $24,65 \pm 0,46 b$ & $22,10 \pm 0,23 c$ & 3,02 & $803,73 * *$ \\
\hline AGS4 & $27,84 \pm 0,66 b$ & $31,48 \pm 0,27 a$ & $32,01 \pm 0,48 a$ & $33,02 \pm 0,07 a$ & 2,79 & $27,23 * *$ \\
\hline AGMI5 & $40,93 \pm 0,66 \mathrm{c}$ & $37,28 \pm 0,39 d$ & $46,81 \pm 0,96 b$ & $50,74 \pm 0,25 a$ & 2,85 & $91,83 * *$ \\
\hline AGPI6 & $31,23 \pm 0,49 a$ & $31,24 \pm 0,50 \mathrm{a}$ & $21,17 \pm 0,51 b$ & $16,24 \pm 0,30 c$ & 3,67 & $268,84 * *$ \\
\hline AGPI/AGS & $1,12 \pm 0,04 \mathrm{a}$ & $0,99 \pm 0,02 b$ & $0,66 \pm 0,01 c$ & $0,49 \pm 0,01 d$ & 5,46 & $171,15^{* *}$ \\
\hline
\end{tabular}

Letras diferentes na mesma linha diferem entre si pelo teste Tukey a $5 \%$ de probabilidade.

$\mathrm{ns}=$ não-significativo, $*(\mathrm{P}<0,05) \mathrm{e}^{* *}(\mathrm{P}<0,01)$.

Dados obtidos com base na porcentagem de área de cada ácido graxo em relação à área total dos ácidos graxos identificados.

1 $\omega 6$ : $\omega 3$ : relação ácidos graxos ômega 6: ácidos graxos ômega 3. 


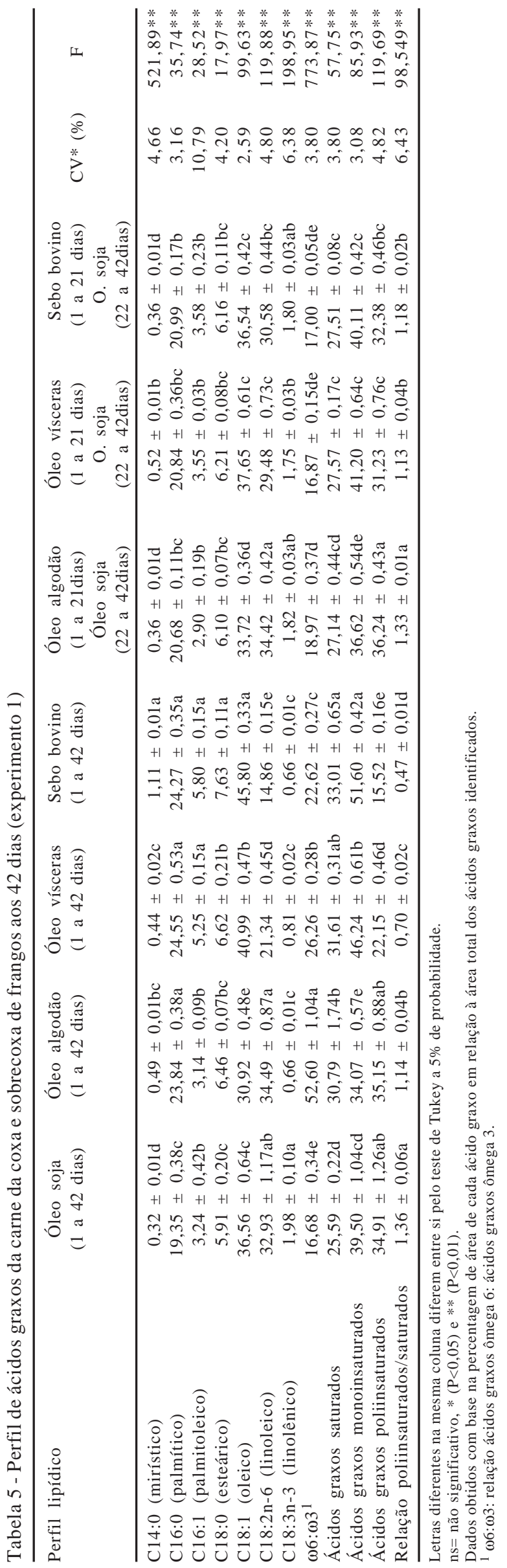

menor relação, porém aves alimentadas por estas fontes na fase inicial eóleo de soja na fase de crescimento, apresentaram relação de ácidos graxos poliinsaturados e de ácidos graxos saturados intermediária às duas fontes lipídicas. As aves alimentadas com sebo bovino na fase inicial, quando passaram a receber óleo de soja na dieta, tiveram a relação de ácidos graxos poliinsaturados e ácidos graxos saturados próxima à das aves alimentadas com óleo de soja por período integral.

Os ácidos graxos poliinsaturados são classificados em n-6 ou n-3 de acordo com a localização das duplas ligações (Schmitz \& Ecker, 2008). As aves que receberam sebo bovino na dieta apresentaram menores teores do ácido linoleico quando comparada às demais fontes. Os mamíferos não sintetizam o ácido graxo linoleico (Schmitz \& Ecker, 2008), possivelmente por isto que o sebo bovino apresenta baixo teor deste ácido.

As aves suplementadas com óleo de soja na fase inicial e de crescimento e óleo de vísceras e sebo bovino na fase inicial tiveram a melhor relação de n-6/n-3. Apesar de as aves que receberam óleo de algodão na dieta apresentarem um alto teor de ácidos graxos poliinsaturados, elas tiveram uma baixa deposição do ácido linolênico, apresentando consequentemente pior relação de $\omega 6: \omega 3$.

Com relação à deposição de ácido linolênico, o menor valor foi observado nas aves que receberam óleo de algodão e sebo bovino na fase inicial e óleo de algodão, óleo de vísceras e sebo bovino na fase inicial e de crescimento.

Os resultados encontrados durante o período de crescimento confirmam a influência da composição lipídica da dieta e do período em que esta é utilizada sobre a deposição dos ácidos graxos na carne da coxa e sobrecoxa.

O melhor perfil de ácidos graxos foi apresentado nas aves alimentadas com óleo de soja na dieta na fase inicial e de crescimento. Estas aves tiveram a maior relação de ácidos graxos poliinsaturados e ácidos graxos saturados e a melhor relação $\omega 6: \omega 3$.

Houve influência significativa sobre os ácidos graxos na carne da coxa (Tabela 7) conforme a fonte lipídica da dieta no experimento 2 (Tabela 6). As aves que receberam dietas contendo lipídios de origem animal depositaram mais ácidos graxos saturados na carne da coxa, refletindo o perfil de ácidos graxos da dieta. Dentre os ácidos graxos saturados identificados, o ácido mirístico foi encontrado em porcentagem maior nas coxas das aves alimentadas com sebo bovino.

O maior teor de ácidos graxos monoinsaturados foi apresentado nas aves alimentadas com dietas contendo sebo bovino e óleo de canola, valores intermediários nas 
Tabela 6 - Perfil de ácidos graxos das rações experimentais na fase de 21 a 42 dias (experimento 2)

\begin{tabular}{|c|c|c|c|c|c|}
\hline Perfil lipídico & Óleo soja & Óleo canola & Óleo girassol & Óleo vísceras & Sebo bovino \\
\hline C16:0 (palmítico) & 11,65 & 8,69 & 8,39 & 20,37 & 21,15 \\
\hline C16:1 (palmitoleico) & 0,14 & 0,17 & 0,14 & 3,58 & 0,96 \\
\hline C18:0 (esteárico) & 3,27 & 3,65 & 3,86 & 4,89 & 21,13 \\
\hline C18:1 (oleico) & 28,31 & 50,99 & 27,89 & 39,17 & 35,60 \\
\hline C18:2n-6 (linoleico) & 52,73 & 34,58 & 58,99 & 30,42 & 18,63 \\
\hline C18:3n-3 (linolênico) & 3,84 & 1,85 & 0,63 & 1,22 & 0,82 \\
\hline Ácidos graxos monoinsaturados & 28,44 & 51,16 & 28,00 & 42,74 & 36,56 \\
\hline Ácidos graxos poliinsaturados & 56,57 & 36,43 & 59,62 & 31,64 & 19,45 \\
\hline Relação poliinsaturados:saturados & 3,78 & 2,94 & 4,83 & 1,24 & 0,44 \\
\hline
\end{tabular}

Dados obtidos com base na percentagem de área de cada ácido graxo em relação à área total dos ácidos graxos identificados

1 $\omega 6: \omega 3$ : relação ácidos graxos ômega 6: ácidos graxos ômega 3.

que receberam óleo de vísceras e menores porcentagens nas que consumiram óleo de soja e óleo de girassol na ração. Este resultado está de acordo com a variação na concentração de ácidos graxos monoinsaturados existente entre as fontes de óleo utilizadas. O fornecimento de lipídios de origem animal na dieta das aves resultou numa maior deposição do ácido palmitoleico.

Quando fornecidas às aves, dietas contendo óleo de soja e óleo de girassol resultaram em maior teor de ácidos graxos poliinsaturados na carne da coxa. Os maiores teores de ácido linoleico foram identificados nas aves que receberam óleo de soja e óleo de girassol, e concentração inferior nas suplementadas com sebo bovino. Quanto à concentração de ácido linolênico, a maior ocorreu nas aves que consumiram dietas contendo OS e as menores nas alimentadas com óleo de girassol e sebo bovino. Possivelmente estes resultados são devidos ao teor de ácido linolênico em cada uma das fontes, as aves que se alimentaram com fontes mais ricas em ácido linolênico depositaram mais quando comparadas às aves que se alimentaram de fontes lipídicas que continham teores menores deste ácido graxo.

A relação poliinsaturados:saturados foi superior nas aves suplementadas com óleo de soja e óleo de girassol, e a menor relação foi obtida nas aves para as quais foi fornecido o sebo bovino como fonte lipídica. Todas as carnes das coxas estudadas apresentaram ácidos graxos poliinsaturados e ácidos graxos saturados superior a 0,40, que é o valor mínimo recomendado pelo Department of Health do Reino Unido, para humanos (Wood et al., 2003).

A melhor relação de $\omega 6: \omega 3$ foi obtida nas aves que receberam óleo de soja, seguida pelas aves que consumiram óleo de canola, sebo bovino e óleo de vísceras. Apesar das aves que receberam óleo de girassol na dieta apresentarem um alto teor de ácidos graxos poliinsaturados, elas tiveram uma baixa deposição do ácido linolênico, apresentando

Tabela 7 - Perfil de ácidos graxos da carne da coxa e sobrecoxa de frangos na fase de 21 a 42 dias (experimento 2)

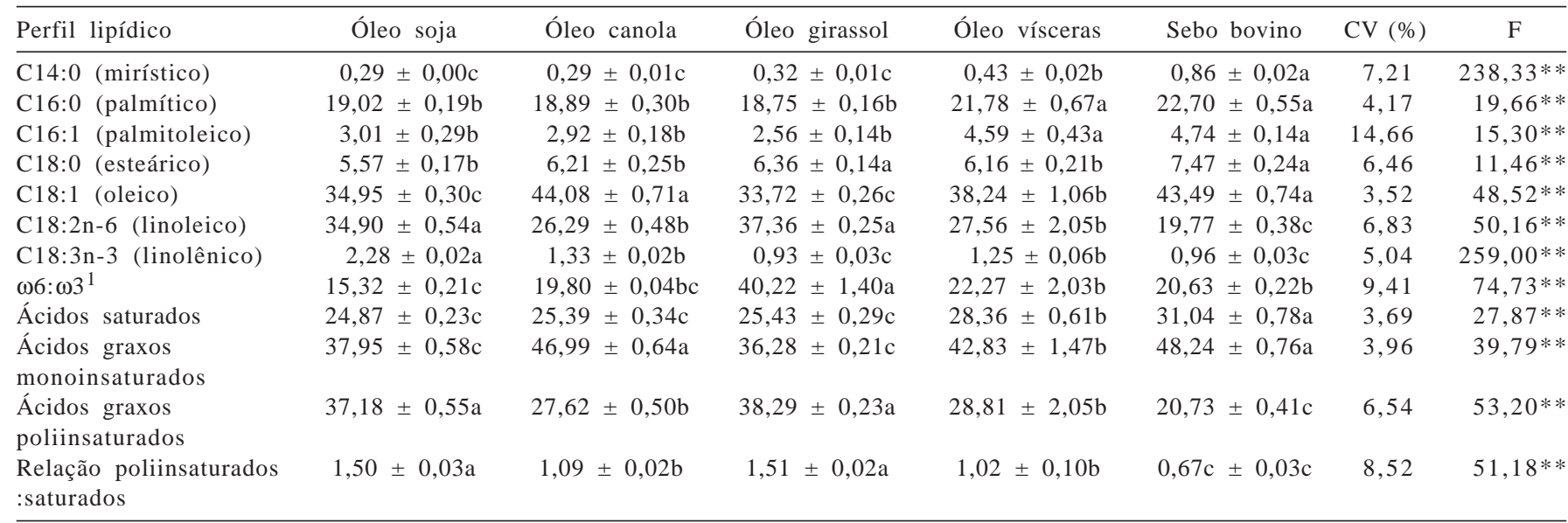

Letras diferentes na mesma linha diferem entre si pelo teste Tukey a 5\% de probabilidade.

ns = não-significativo, $*(\mathrm{P}<0,05) \mathrm{e} * *(\mathrm{P}<0,01)$.

Dados obtidos com base na percentagem de área de cada ácido graxo em relação à área total dos ácidos graxos identificados

1 $\omega 6: \omega 3$ : relação ácidos graxos ômega 6: ácidos graxos ômega 3. 
consequentemente pior relação de $\omega 6: \omega 3$. Os resultados encontrados sugerem que o enriquecimento das dietas com diferentes fontes de óleo, ricas em ácidos graxos poliinsaturados das séries n-3 e n-6, promovem modificações na composição lipídica na carne da coxa das aves.

Segundo Simopoulos et al. (1999), é recomendada uma redução na relação n-6 e n-3 na dieta de adultos e recémnascidos, para um metabolismo cardiovascular e um funcionamento cerebral adequados. Garófolo \& Petrilli (2006) citaram que as famílias de ácidos $\omega 6: \omega 3$ competem pelas mesmas enzimas, sendo de grande importância o balanço entre estes ácidos.

A concentração dos ácidos graxos saturados na carne de aves, principalmente o palmítico e esteárico, é muito resistente às mudanças e é pouco influenciada pelo conteúdo lipídico da dieta (Simopoulos, 2000). No entanto, em ambos os experimentos, na fase de 1 a 21 dias e de 22 a 42 dias, as concentrações de ácido palmítico e esteárico foram influenciadas pela dieta. Provavelmente este efeito seja devido à grande diferença na concentração destes ácidos entre as rações estudadas.

De acordo com Pinchasov \& Nir (1992), os ácidos graxos poliinsaturados são mais efetivos na redução de ácidos graxos monoinsaturados do que ácidos graxos saturados e inibem a atividade da enzima desaturase na formação do ácido oleico. Os resultados encontrados neste experimento concordaram com os referidos autores, onde as fontes ricas em ácidos graxos poliinsaturados proporcionaram menores concentrações de ácido oleico na carne das coxas e sobrecoxas de frangos.

Neste experimento, o melhor perfil de ácidos graxos foi identificado nas aves alimentadas com óleo de soja na dieta, por apresentar uma alta relação de $\omega 6: \omega 3$ e maior razão de ácidos graxos poliinsaturados e ácidos graxos saturados.

As fontes lipídicas do experimento 2 não influenciaram a força de cisalhamento da carne do peito (Tabela 8) nas diferentes fontes lipídicas que as aves receberam. A carne é considerada macia quando apresenta valores de força de cisalhamento de 8 a 11 kgf e dura acima de 11 kgf

Tabela 8 - Valores de pH e força de cisalhamento da carne do peito de frangos de corte aos 42 dias (experimento 2)

\begin{tabular}{lcc}
\hline Fonte de lipídios & $\mathrm{pH}$ & Força \\
\hline Óleo sojasalhamento & (kgf) \\
Óleo canola & $5,84 \pm 0,04$ & $5,09 \pm 0,52$ \\
Óleo girassol & $5,82 \pm 0,04$ & $4,99 \pm 0,33$ \\
Óleo vísceras & $5,89 \pm 0,03$ & $3,87 \pm 0,51$ \\
Sebo bovino & $5,80 \pm 0,05$ & $5,36 \pm 0,68$ \\
CV (\%) & $1,79 \pm 0,04$ & $4,37 \pm 0,49$ \\
F & $0,89 \mathrm{~ns}$ & 26,70 \\
\hline
\end{tabular}

Tukey, $\mathrm{P}>0,05$.

ns $=$ não-significativo, $*(\mathrm{P}<0,05) \mathrm{e}^{* *}(\mathrm{P}<0,01)$
(Bickerstaffe et al., 1997), e com base neste critério as carnes analisadas podem ser consideradas macias. O colágeno interfere na textura da carne - animais jovens apresentam menores números de pontes cruzadas de colágeno que se quebram facilmente - e a síntese de colágeno novo é mais rápida quando comparada a animais velhos (Bailey, 1985). Como os animais foram abatidos jovens, possivelmente a idade de abate tenha influenciado os resultados.

$\mathrm{O} \mathrm{pH}, 4$ horas post-mortem da carne de peito dos frangos (Tabela 8) não foi influenciado pelo perfil lipídico da dieta. $\mathrm{O}$ valor do $\mathrm{pH}$ de um músculo vivo é ligeiramente superior ao ponto neutro ( $\mathrm{pH} 7,2)$. Após o abate, o processo bioquímico da carne continua transformando o conteúdo energético do músculo em glicogênio lático sob ação de várias enzimas - esse processo chama-se glicólise anaeróbica. Pela formação ácida, o valor do $\mathrm{pH}$ da carne diminui. Geralmente a carne de peito de frango apresenta $\mathrm{pH}$ final que varia de 5,7 a 5,9, em carne normal (Souza, 2007). A média do $\mathrm{pH}$ da carne de peito dos frangos 4 horas postmortem foi de 5,83. Provavelmente o $\mathrm{pH}$ post-mortem esteja mais correlacionado a outros fatores como o estresse pré-abate do que com o perfil lipídico da dieta.

\section{Conclusões}

As fontes de lipídio da ração influenciam o perfil de ácidos graxos da carne de coxa e sobrecoxa, porém, em níveis de 3 a 4,5\% de inclusão, não influenciam o pH nem a força de cisalhamento. A carne da coxa e sobrecoxa das aves apresentam perfil lipídico próximo ao da fonte utilizada nas dietas na fase de crescimento. Aves que recebem óleo de soja e óleo de canola na ração apresentam melhor relação de $\omega 6: \omega 3$ e melhor relação de ácidos graxos poliinsaturados e ácidos graxos saturados em comparação a aves que recebem apenas óleo de soja na dieta. Assim, o uso de óleo de soja na ração de frangos de corte, tanto na fase inicial quanto na de crescimento, pode melhorar o melhor perfil de ácidos graxos na carne da coxa.

\section{Referências}

ANDREOTTI, M.O.; JUNQUEIRA, O.M.; BARBOSA, M.J.B. et al. Energia metabolizável do óleo de soja em diferentes níveis de inclusão para frangos de corte nas fases de crescimento e final. Revista Brasileira de Zootecnia, v.33, n.5, p.1145-1151, 2004.

ARTERBURN, L.M.; HALL, E.B.; OKEN, H. Distribution, interconversion, and dose response of n-3 fatty acids in humans. American Journal Clinical Nutrition, v.83, p.1467-1476, 2006.

BAILEY, A.J. The role of collagen in the development of muscle and relationship to eating quality. Journal of Animal Science, v.60, p.1580-87, 1985. 
BICKERSTAFFE, R.; Le COUTEUR, C.E.; MORTON, J.D. Consistency of tenderness in New Zealand retail meat. In: INTERNATIONAL CONGRESS OF MEAT SCIENCE AND TECHNOlOGY, 43., 1997, Auckland. Proceedings... Auckland, Nova Zelândia, 1997. p.196-197.

BLIGH, E.G.; DYER, W.J. A rapid method of total lipid extraction and purification. Biochemistry and Physiology, v.37, n.8, p.911-917, 1959.

BURDGE, G. $\alpha$-linolenic acid metabolism in men and women: nutritional and biological implications. Current Opinion. Clinical. Nutrition. Metabolic Care, v.7, p.137-144, 2004.

COSTA, F.G.P.; SOUZA, C.J.S.; GOULART, C.C. et al. Desempenho e qualidade dos ovos de poedeiras semipesadas alimentadas com dietas contendo óleos de soja e canola. Revista Brasileira de Zootecnia, v.37, n.8, p.1412-1418, 2008.

CRESPO, N.; ESTEVE-GARCIA, E. Dietary polyunsaturated fatty acids decrease fat deposition in separable fat depots but not in the remainder carcass. Poultry Science, v.81, p.512-518, 2002.

FAGUNDES, L.A. Ômega-3 e ômega-6: O equilíbrio dos ácidos gordurosos essenciais na prevenção de doenças. Porto Alegre: Fundação de Radioterapia do Rio Grande do Sul, 2002. 111p.

FRENCH, P.; STANTON, C.; LAWLESS, F.; et al. Fatty acid composition, including conjugated linoleic acid, of intramuscular fat from steers offered grazed grass, grass silage, or concentratebased diets. Journal of Animal Science, v.78, p.2849-2855, 2000 .

GARÓFOLO, A.; PETRILLI, A.S. Balanço entre ácidos graxos omega-3 e 6 na resposta inflamatória em pacientes com câncer e caquexia. Nutrição, v.19, n.5, p.611-621, 2006.

GEBAUER, S.K.; PSOTA, T.L.; HARRIS, W.S. n-3 fatty acid dietary recommendations and food sources to achieve essentiality and cardiovascular benefits. American Journal Clinical Nutrition, v.83, p.1526-1535, 2006.

HARRIS, W. Fish oils, omega-3 polyunsaturated fatty acids, and coronary heart disease. Backgrounder, v.2, n.1, p.1-8, 1997.

INTERNATIONAL ORGANIZATION FOR STANDARDIZATION - ISO. Animal and vegetable fats and oils - Preparation of methyl esters of fatty acids. Method ISO 5509, 1978.

JUNQUEIRA, O.M.; ANDREOTTI, M.O.; ARAÚJO, L.F. et al. Valor energético de algumas fontes lipídicas determinado com frangos de corte. Revista Brasileira de Zootecnia, v.34, n.6, p.2335-2339, 2005 (supl.).

KERTH, C.R.; MILLER, M.F.; RANSEY, C.B. Improvement of beef tenderness and quality traits with calcium chloride injection in beef loins 48 hours post mortem. Journal of Food Science, v.73, p.750-756, 1995.

LABORDE, F.L.; MANDELL, I.B.; TOSH, J.J. et al. Breed effects on growth performance, carcass characteristics, fatty acid composition, and palatability attributes in finishing steers. Animal Science, v.79, p.355-365, 2001.

LARA, L.J.C.; BAIÃO, N.C.; AGUILAR, C.A.L. et al. Rendimento composição e teor de ácidos graxos da carcaça de frangos de corte alimentados com diferentes fontes lipídicas. Arquivo Brasileiro de Medicina Veterinária e Zootecnia, v.58, n.1, p.108-115, 2006.

METZ, D.A.; KRIS_ETHERTON, P.M.; MORRIS, C.D. et al. Dietary compliance and cardiovascular risk reduction with a prepared meal plan compared with a self-selected diet. Clinical of Nutrition, v.66, p.373-385, 1997.

MORGAN, J.B.; WHEELER, T.L. KOOHMARAIE, M. et al. Effect of castration on myofibrillar protein turnover, endogenous proteinase activities, and muscle growth in bovine sketetal muscle. Animal Science, v.71, p.408-414, 1993.

NASCIF, C.C.C.; GOMES, P.C.; ALBINO, L.F.T. et al. determinação dos valores energéticos de alguns óleos e gorduras para pintos de corte machos e fêmeas aos 21 dias de idade. Revista Brasileira de Zootecnia, v.33, n.2, p.375-385, 2004.

OLIVER, M.F. It is more important to increase the intake of unsaturated fats than to decrease to intake of saturated fats: evidence from clinical trials relating to eschemic hearth disease. Clinical of Nutrition, v.66, p.980S-986S, 1997 (supplement).

PINCHASOV, Y.; NIR, I. Effect of de dietary polyunsaturated fatty acid concentration on performance, fat deposition and carcass fatty acid composition in broiler chickens. Poultry Science, v.71, p.1504-1512, 1992.

RIBEIRO, P.A.P.; LOGATO, P.V.R.; PAULA, D.A.J. et al. Efeito do uso de óleo na dieta sobre a lipogênese e o perfil lipídico de tilápias-do-nilo. Revista Brasileira de Zootecnia, v.37, n.8, p.1331-1337, 2008.

RIQUE, A.B.R.; SOARES, E.A.; MEIRELLES, C.M. Nutrição e exercício na prevenção e controle das doenças cardiovasculares. Revista Brasileira de Medicina do Esporte, v.8, n.6, p.244-254, 2002.

ROSTAGNO, H.S.; ALBINO, L.F.T.; DONZELE, J.L. et al. Tabelas brasileiras para aves e suínos: composição de alimentos e exigências nutricionais. 2.ed. Viçosa, MG: UFV, 2005. 186p.

SCHMITZ, G.; ECKER, J. The opposing effects of n-3 and n-6 fatty acids. Progress in Lipid Research, v.47, p.147-155, 2008.

SIMOPOULOS, A.P.; LEAF, A.; SALEM JR., N. Essentiality of and recommended dietary intakes for omega- 6 and omega-3 fatty acids. Nutrition and Metabolism, v.43, p.127-130, 1999.

SIMPOULOS, A.P. Symposium: role of poultry products in enriching the human diet with n-3 pufa. Poultry Science, v.79, p.961-970, 2000.

SOUZA, H.B.A. [2006] Parâmetros físicos e sensoriais utilizados para Avaliação de qualidade da carne de frango. Disponível em <http://www.cnpsa.embrapa.br/down.php?tipo= publicacoes\&cod_publicacao=793> Acesso em: 19/12/2007.

TARRANT, V. Prioridades na pesquisa para a industria da carne, In: CONGRESSO BRASILEIRO DE CIÊNCIA E TECNOLOGIA DE CARNES, 1., 2001, São Pedro. Anais... Campinas: Ital, 2001. p.380, 2001.

UNIVERSIDADE FEDERAL DE VIÇOSA - UFV. Sistema para Análises Estatísticas e Genéticas - SAEG. Viçosa, MG, 1993. 59p.

WATTS, G.F.; JACKSON, P.; BURKE, V. et al. Dietary fatty acids and progression of coronary artery disease in men. Clinical of Nutrition, v.64, n.2, p.202-209, 1996.

WOOD, J.D.; RICHARDSON, R.I.; NUTE, G.R. et al. Effects of fatty acids on meat quality: a review. Meat Science, v.66, p.21-32, 2003.

ZUIDHOF, M.J.; BETTI, M.; KORVER, D.R. et al. Omega-3 enriched broiler meat: 1. Optimization of a production system. Poultry Science, v.88, p.1108-1220, 2009. 